\title{
Diagnosis and management of a full thickness macular hole
}

\author{
BY NICOLAS FONTAINE 1 , OD, MSC. \\ SÉBASTIEN OLIVIER², MD, OD
}

\section{Introduction}

\section{macular hole is a condition 1 where part (lamellar macular hole - LMH) or the full extent (full-thickness macular hole -} FTMH) of the sensory retina is detached from the rest of the retina, in the central or macular region of the retina. The diagnosis is usually quick, because most pa-

\section{RÉSUMÉ}

Contexte: Les trous maculaires ne sont pas toujours faciles à identifier à un stade précoce, à moins de procéder à des tests d'imagerie médicale. Le diagnostic différentiel par rapport à d'autres atteintes maculaires est souvent possible pour un oeil expérimenté grâce à l'utilisation d'une lentille binoculaire de fond d'œil. Cependant, l'avènement de la tomographie à cohérence optique facilite un diagnostic exact.

Rapport de cas: Ce rapport montre un cas classique de trou maculaire de pleine épaisseur. Les signes cliniques ne sont pas pathognomoniques au début, mais des signes probants se développeront dans les semaines suivantes. Les différentes étapes de la maladie sont décrites, de même que les modalités de traitement chirurgical et les résultats attendus.

Conclusions : Un diagnostic précoce permet une récupération rapide de la vision. Néanmoins, cette atteinte peut être traitée jusqu'à un an après l'apparition des premiers signes avec une amélioration significative de la fonction visuelle. tients report severe impairment of central vision, which develops over the course of a few days or weeks at most. Evidence obtained with retinal imagery, mostly Optical Coherence Tomography (OCT), seems to indicate that separation of part or the entire extent of the retina results from an abnormal vitreo-foveolar attachment. ${ }^{1}$ In many instances, the presence of an epiretinal membrane (ERM) connecting the sensory retina to the vitreous body has been noted. ${ }^{1}$ With senescence, the vitreous

\section{ABSTRACT}

Background: First stage macular holes are not always easily identified without the use of medical imagery. Differential diagnosis from other macular conditions is possible with a keen eye and the use of a binocular fundus lens. However, the advent of optical coherence tomography facilitates accurate diagnosis.

Case Report: This report demonstrates a classical case of a full thickness macular hole. The clinical signs are not pathognomonic at first, but typical signs develop in the following weeks. The different stages of the disease are described, as well as current state of surgical treatment and possible outcomes.

Conclusions: Early diagnosis allows quick visual recovery. Nevertheless, this condition can be treated up to one year after occurrence with significant improvement of visual function.

Key words: full-thickness macular hole (FTMH), Optical Coherence Tomography (OCT), pars plana vitrectomy (PPV), membrane peeling, gas tamponade
1 Assistant professor, École d'Optométrie, Université de Montréal

2 Lecturer, Department of Ophthalmology, Faculty of Medicine, Université de Montréal

body, contained in the central cavity of the ocular globe, shrinks and liquefies. The hyaloid membrane, which envelops the vitreous, detaches itself from the inner limiting membrane (ILM) of the retina. If abnormally high adherence exists between both structures, anteroposterior and tangential forces are exerted on the surface of the retina. ${ }^{2}$ As a result, part of the sensory retina is pulled away and may ultimately be torn away. Intravitreal fluid will seep through the hole and detach and disorganize the surrounding photoreceptors of the macular region. ${ }^{3}$ The process leading to the diagnosis of a full-thickness macular hole is illustrated in this case report, followed by successful treatment and resolution of the condition.

\section{Case report}

A 65-year-old Caucasian female presented to our clinic on November 16th, 2010 with complaints of a "black dot" in the center of the visual field of the right eye which appeared one week before and had been growing since. Vision from this eye had been blurred for almost a month. She was a patient 
of our clinic for 11 years, and suffered from minor water retention and dyslipidemia. Her medications were risedronate sodium $5 \mathrm{mg}$ (Actonel $^{\mathrm{TM}}$ ), atorvastatin calcium $10 \mathrm{mg}$ (Lipitor ${ }^{\mathrm{TM}}$ ), calcium carbonate $1500 \mathrm{mg}$ (Caltrate ${ }^{\mathrm{TM}}$ ), furosemide $20 \mathrm{mg}$ (Lasix $\left.{ }^{\mathrm{TM}}\right)$ and vitamin B12. She reported no allergies. Routine ocular fundus photography had been performed with a Canon CR-DGi camera (Japan) on her last routine exam on October 1st 2007 (right eye shown on Figure 1). Aside from some small drusen at the macula OU, there were no particular ocular findings. Bestcorrected Snellen distance visual acuity (BCVA) was 6/6 (20/20) for each eye, with $-0.75 \mathrm{D}$ correction OU.

Her corrected visual acuity (VA) was now 6/24+1 (20/80+1) OD and $6 / 7.5+1(20 / 25+1)$ OS. Pinholes provided no improvement. Pupils were equally round and reactive to light, and no afferent pupillary defect was noted. Anterior segment evaluation by slit lamp examination was within normal limits. Amsler grid testing was normal OS, however, a small central metamorphopsia was documented OD. The patient's pupils were then dilated. The results of an evaluation of the posterior segment by slit lamp with a 78D fundus lens and by binocular indirect ophthalmoscope were all normal except that the macula of the right eye presented with a small light grey flat lesion with diffuse border (Figure 2), the macula of the left eye (not shown on the figure) showed 5 small drusen. There was no foveal reflex in either eye. The

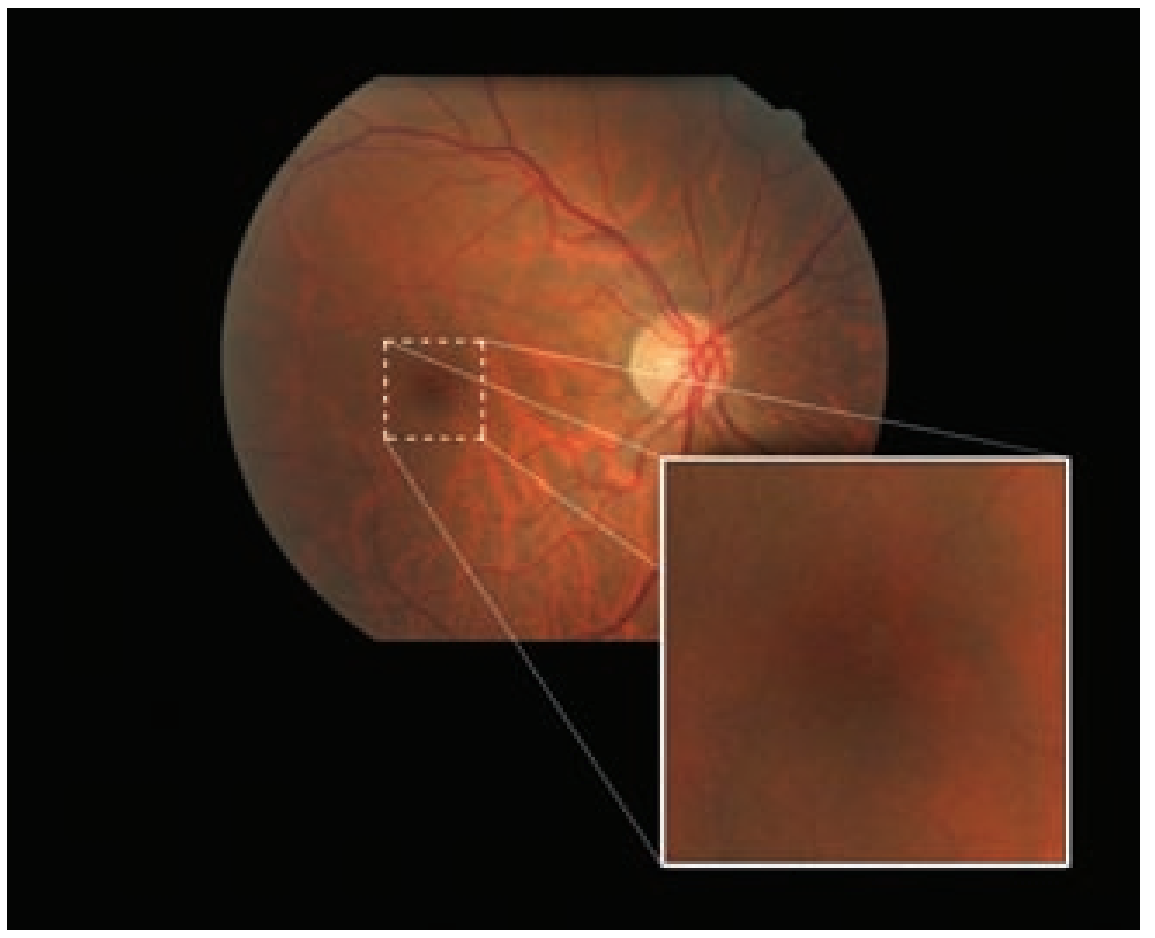

Figure 1 - Fundus photography shows small macular drusen in the right eye.

vitreous was clear $\mathrm{OU}$ with no presence of a Weiss's ring in either eye. The Watzke-Allen test was performed on the right eye with negative result.

\section{The differential diagnosis included ruling out:}

- Solitary drusen

- Advanced dry age-related macular degeneration (AMD)

- Wet age-related macular degeneration (AMD)

- Lamellar macular hole (LMH)

- Full-thickness macular hole (FTMH)

- Epiretinal membrane with pseudo macular hole

- Central serous retinopathy

- Vitreomacular traction syndrome

- Cystoid macular edema

The small drusen observed in the left eye are usually suggestive of the dry form of AMD. However, the lesion seen in the right eye did not present the usual yellow color of a drusen.

Sub- or intraretinal hemorrhages resulting from wet AMD are normally of a dark color rather than light grey. However, this lesion could still be some form of exudation.

LMH and FTMH, as well as wet AMD, may present with such a sudden onset. Moreover, this greyish lesion could be detached retinal tissue. However, our office is not equipped with an OCT, so it was not possible at this stage to determine precise anatomic positioning of the sensory retina.

An epiretinal membrane with pseudo macular hole was possible, although such a membrane had not been observed on previous examinations. Again, the use of an 


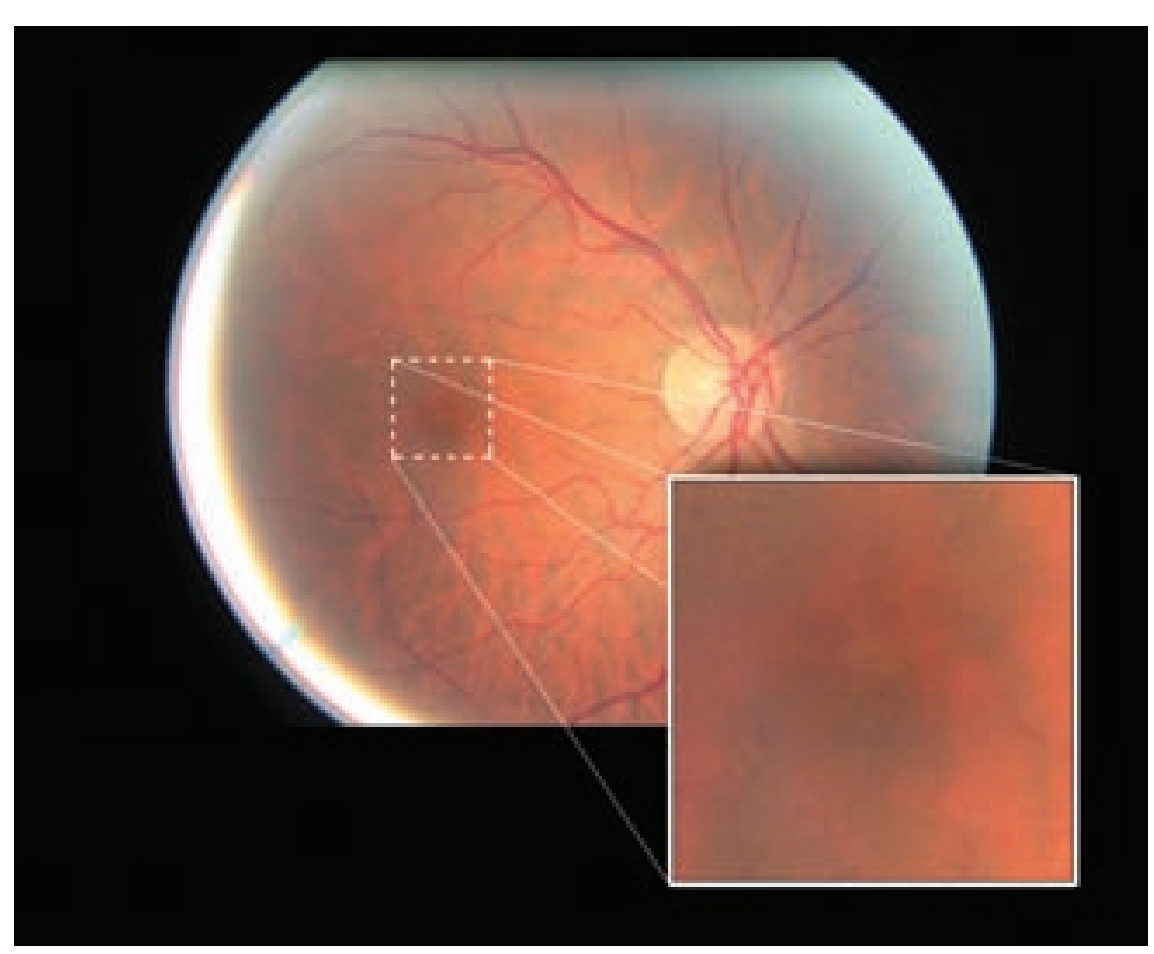

Figure 2 - Fundus photography shows a small light grey flat lesion with diffuse border in the right eye.

OCT would have been helpful in identifying a subtle membrane.

Vitreomacular traction syndrome and cystoid macular edema would show the presence of retinal cysts while none had been observed. An OCT examination could help to rule-out more subtle manifestations of those entities.

Central serous retinopathy was ruled out since there was no significant elevation of the macular region. Moreover, this condition typically affects males between the age of 20 and 50, but it is sometimes observed in women also, although more rarely.

Definitive diagnosis seemed to warrant the use of computerized imagery of the retina such as OCT.
Best-corrected distance visual acuity was now 6/45 (20/150) OD and 6/7.5-1 (20/25-1) OS. The patient's right eye was dilated. This "swinging spot" had the characteristics of a macular operculum and since no standard contact lens for fundus observation was available, this time she was examined with the central lens of the Goldmann 3-mirror lens. Suspicions of a macular hole were confirmed by the presence of a floating operculum above the macula of the right eye. Vitreous detachment was at an early stage at this time, if any, since no Weiss's ring was observed floating in the posterior chamber.

The retinal specialist was contacted the next day and an appointment was scheduled.

\section{Visit with the retinal specialist}

The patient met with the retinal specialist on January 7th, 2011. Best-corrected distance Snellen visual acuity was 6/30- (20/100-) OD and 6/6- (20/20-) OS. Fundus examination showed a lesion of the macula of the right eye and no presence of a Weiss's ring in either eye. An OCT examination was performed using the Stratus OCT ${ }^{\mathrm{TM}}$ from Zeiss (Germany) (right eye shown on Figure 3).

OCT for the right eye showed a full thickness macular hole with sensory retinal detachment around the hole. Infiltration of fluid through intraretinal spaces produced cystic changes around the hole. A pseudo-operculum could also be observed attached to the posterior hyaloid membrane and floating above the fovea. OCT for 
the left eye showed a normal appearance of the macular region.

These observations lead the retinal specialist to the diagnosis of a stage 3 macular hole. He suggested 25-gauge pars-plana vitrectomy with air tamponade and phacoemulsification. He also informed the patient of a $1 / 100$ chance of worse vision after the surgery and of a 1/1,000 risk of losing the eye. The patient chose to proceed with the intervention.

\section{Surgery}

On February 15th, 2011, the retinal specialist proceeded with the surgery. He used retrobulbar injection for anesthesia. He started with cataract extraction using phacoemulsification. He then performed the vitrectomy, and injected intravitreous triamcinolone acetonide (Kenalog ${ }^{\mathrm{TM}}$ ) before conducting a peeling of the internal limiting membrane that he had stained with infracyanine green (IFCG). Finally, fluid air exchange was performed using 20\% sulphur hexafluoride (SF6). The patient was instructed to maintain a prone position for the better part of seven days. She was scheduled for a follow-up the next morning.

\section{Next day post-op visit}

On February 16th, 2011, visual acuity for the right eye was "hand motion". Slit-lamp examination showed a well-sutured wound and grade 3 cell reaction in the anterior chamber. On fundus examination, the retina was on and the gas bubble at $90 \%$ of its volume. Moxifloxacine chlorhydrate $0.5 \%$
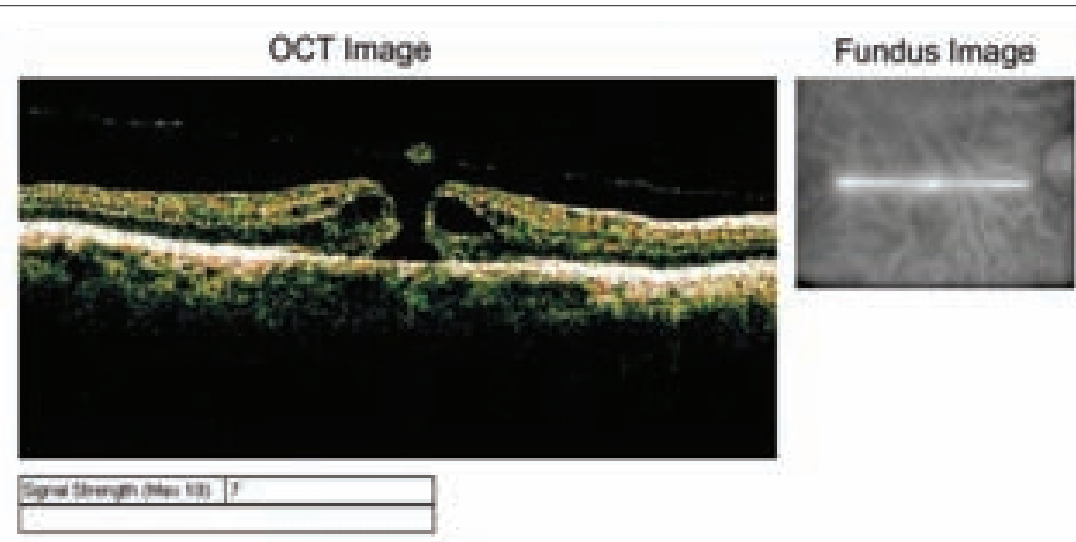

\section{Scanned Image}
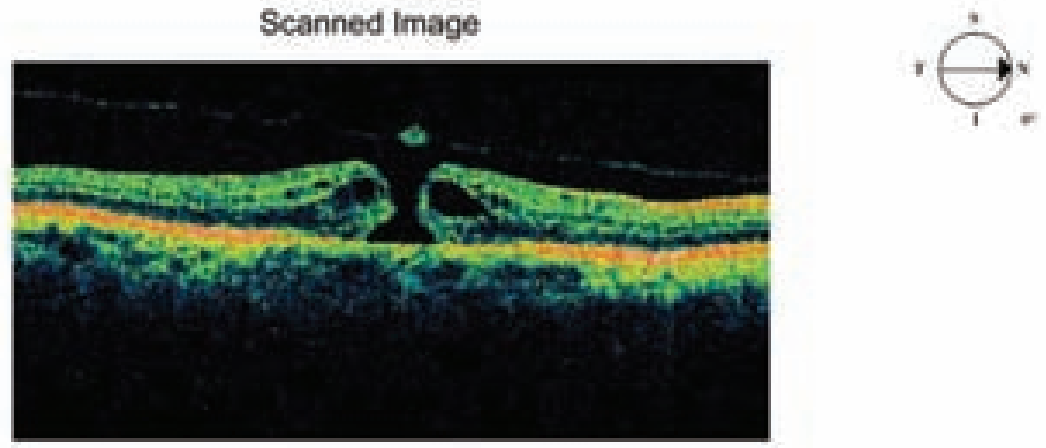

Figure 3-OCT shows a full thickness macular bole with pseudo-operculum and surrounding sensory retina detachment in the right eye.

(5 mg/mL) (Vigamox ${ }^{\mathrm{TM}}$ ) q.i.d., prednisolone acetate $1.0 \%$ (Pred Forte $\left.^{\mathrm{TM}}\right)$ q.i.d. and homatropine $5.0 \%$ q.i.d. were prescribed for the right eye and a follow-up was scheduled for the following week.

\section{One-week post-op visit}

On February 22nd, 2011, uncorrected Snellen visual acuity OD was 6/18-1 (20/60-1) and corrected visual acuity OS was 6/7.5 (20/25). Slit-lamp examination of the right eye showed a well-sutured wound and grade 1 cell reaction in the anterior chamber. Contact lens fundus examination showed a closed macular hole. The same medication was prescribed for the right eye and a follow-up was scheduled for the next month.

\section{Five-week post-op visit}

On March 25th, 2011, uncorrected Snellen visual acuity OD was $6 / 24+2(20 / 80+2)$ and corrected visual acuity OS was 6/6- (20/20-). Slit-lamp examination of the right eye showed a well-sutured wound and quiet anterior chamber and the beginning of a posterior capsule opacification. Contact lens fundus examination showed a closed macular hole. OCT of the right eye portrayed a normal looking macula very similar to the OCT of the left macula (right eye only shown on Figure 4). Pred Forte 1.0\% was 


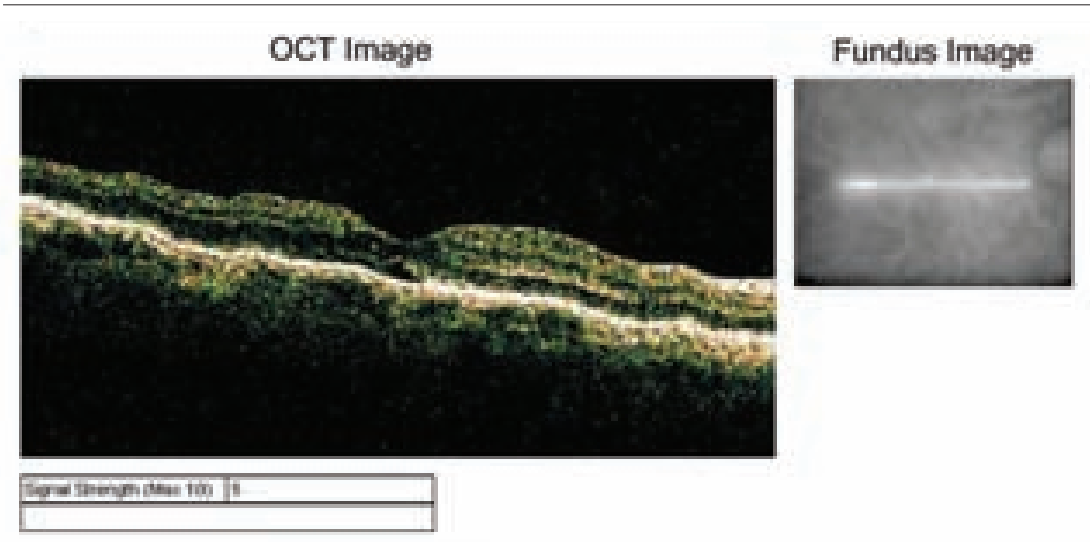

Scanned Image

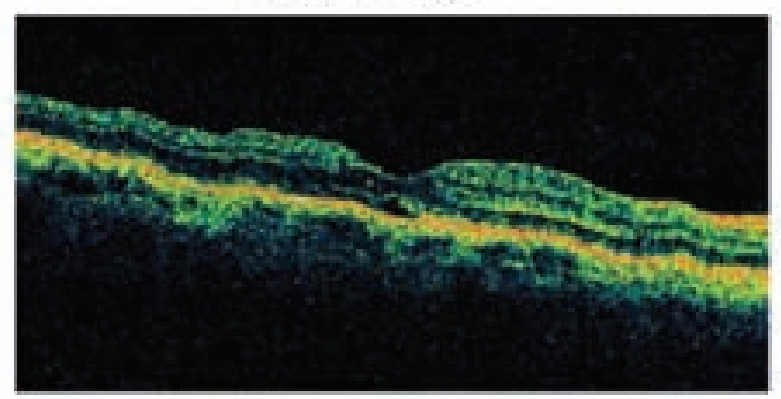

Figure 4-OCT of the right eye shows a closed macular hole and normalized macular structure in the right eye.

tapered, Vigamox 0.5\% (5 mg/ $\mathrm{mL}$ ) and homatropine 5\% were stopped for the right eye. YAG laser capsulotomy was scheduled for the next follow-up.

\section{Two-month post-op visit}

On April 12th, 2011, uncorrected Snellen visual acuity OD was $6 / 12$ (20/40). YAG laser capsulotomy was performed on the right eye. One drop of brimonidine tartrate $0.15 \%$ Alphagan $^{\mathrm{TM}}$ ) was used pre-op. Pred Forte 1.0\% was prescribed q.i.d. for one week. Followup was scheduled in two months. The patient was advised to return to the referring optometrist for refraction.

\section{Thirteen weeks post-op visit}

On May 6th, 2011, the patient had an appointment at our clinic for refraction. She said that she was satisfied with the vision of her right eye even though it was not as good as it was before the "incident".

Prescription of the habitual pair of glasses was OD -0.50$0.25 \times 090$ and OS -0.50, addition +2.75 OU. Snellen distance visual acuity with this correction was 6/12 (20/40) OD and 6/6 (20/20) OS. However, the patient pointed out that the letters were "not completely formed" on their right side. Binocular reading was $\mathrm{J} 2$ at 40 centimeters (16 inches). Results of subjective refraction were OD $-0.75-0.50 \times 1806 / 12+2$ $(20 / 40+2)$ and OS $-0.75-0.25 \times$ $1006 / 6(20 / 20)$ with +3.00 addition for $6 / 6(20 / 20)$ binocular visual acuity at near. Anterior segment evaluation by slit lamp examination was within normal limits. The macula of the right eye presented a closed macular hole with well-defined borders and no sign of infiltration (Figure 5); the macula of the left eye (not presented on the figure) showed unchanged appearance of drusen. There was no foveal reflex in either eye.

Amsler grid testing was normal in the left eye; however, a small central metamorphopsia was noticed on the right of the fixation point in the right eye. This corresponded to the patient's reported area of distortion on the right side of the letters on the Snellen chart. Humphrey HFA-750 ${ }^{\mathrm{TM}}$ (Zeiss/ Humphrey instruments, Germany) macular threshold automated perimetry was performed. A very small loss of sensitivity was observed for the right eye compared with the left eye ( 2 to $5 \mathrm{~dB}$ less depending on the region tested and not statistically significant according to the instrument).

The patient was informed of the very good result of the surgery and about a potential small distortion remaining in the vision of the right eye due to the retinal tear. However, the rest of the retina was well reattached and would, in all likelihood, remain so. She was advised that a macular hole could also happen in the other eye, as bilateral onset occurs in about $10-15 \%$ of cases but it is 
rarely simultaneous. ${ }^{4,6}$ As for her glasses, it was explained to her that there was very little change in the prescription. Annual routine exams were advised, but the patient was counseled to keep careful watch over the vision of both eyes and to keep using her Amsler grid. In the case of broken or distorted lines, or sudden appearance of a dark spot in the center of the grid, she should be assessed as soon as possible.

\section{Discussion}

Age-related FTMH is a fairly rare occurrence: it is found in 3 out of 1,000 individuals $^{4}$ and affects primarily females 3:15. It is believed to be the result of an abnormally strong adherence between the posterior hyaloid membrane of the vitreous body and the central or macular part of the sensory retina. An example of this is vitreomacular syndrome where there is an incomplete separation of the vitreous from the retina with persistent macular attachment. ${ }^{1}$ When posterior vitreous detachment occurs, the force transmitted to the surface of the macula may tear part of the retina off. Fluid from the vitreous cavity infiltrates the outer layers of the retina and detaches the photoreceptors from the retinal pigment epithelium. The resulting disorganization of the photoreceptors leads to a severe loss of visual acuity, as well as possible perception of metamorphopsia or of a central scotoma.

Etiology is mostly idiopathic. However, other risk factors include: cystoid macular edema, vitreomacular reaction, trauma, ocular surgery, myopia, laser treatment and intraocular inflammation. ${ }^{5}$

Traditionally, diagnosis was made through the observation of the macular area with a noncontact fundus lens (Hruby, Volk, etc.), or preferably with a contact fundus lens, which provides better resolution of fine details of retinal structures as well as better stability. A subjective assessment can also be obtained with the Watzke-Allen test. This test involves projecting a fine vertical slit on the retina, with the slit lamp and a fundus lens, and sweeping this slit laterally on the macular area. In the presence of a full thickness hole, the subject should report a break in the middle part of the slit as it passes over the hole.

More detailed observation and better identification of the different stages of the disease are obtained nowadays with the use of the OCT. ${ }^{6}$

Stage 1: (impending or pre-macular hole): there is a perifoveal PVD with persistent attachment of the posterior hyaloid to the foveal center. At this stage, there is loss of the foveal reflex.

- Stage 1A: the antero-posterior traction resulting from stage 1 leads to an intrafoveal cyst. This cyst can often be observed as a yellow spot.

- This stage $1 \mathrm{~A}$ hole can evolve in three ways:

- The hyaloido-foveal attachment can break, with resolution of the cyst and return to a normal foveal configuration.
- The hyaloido-foveal attachment can break the inner wall of the intrafoveal cyst, with evolution to an inner lamellar hole.

- There can be disruption of the outer wall of the intrafoveal cyst, with evolution to a stage $1 \mathrm{~B}$ hole - outer lamellar hole.

- A yellow ring is observed around the fovea in a stage $1 \mathrm{~B}$ hole and is most likely due to disruption of the xanthophyll within the outer wall of the intrafoveal cyst. Visual acuity is usually around $6 / 7.5(20 / 25)$ to $6 / 18(20 / 70)$.

Stage 2: (full-thickness hole): there is still a perifoveal PVD with persistent attachment of the posterior hyaloid to the foveal center. The resultant antero-posterior traction leads to a full-thickness disruption of the neuroepithelium. An incomplete prefoveal operculum begins to detach, to which the posterior hyaloid is still connected. The hole is less than $400 \mu \mathrm{m}$ diameter.

Stage 3: (full-thickness hole): the posterior hyaloid detaches from the foveal centre and so does the prefoveal operculum. However, the hyaloid remains attached outside of the macular area. The diameter of the hole is between 400 and 600 $\mu \mathrm{m}$. Visual acuity is usually around $6 / 18(20 / 70)$ to $6 / 120(20 / 400)$.

Stage 4: the posterior hyaloid is detached all the way to the periphery. Visual acuity is decreased and there is an absolute central scotoma, surrounded by a relative scotoma owing to the subretinal infiltration. Visual acuity is usually 
around $6 / 60(20 / 200)$ to $6 / 120$ (20/400). With time, small yellow precipitates may be seen at the bottom of the hole, deep to the retina. Cystoid retinal changes may be present at the hole margins. Unless major traction exists on a large surface of the posterior pole, as could be the case with a neovascular membrane in proliferative diabetic retinopathy for example, detachment of the sensory retina and subretinal fluid infiltration are rather limited in the case of a macular hole and visual acuity usually stabilizes around $6 / 60(20 / 200)$ to $6 / 120(20 / 400){ }^{4}$

When our patient met with the retinal specialist for the first time, the OCT revealed the presence of a full-thickness defect with a prefoveal operculum. The ophthalmologist also wrote on the patient's chart that there was no Weiss's ring in the vitreous cavity OU. $\mathrm{He}$ concluded that the posterior part of the vitreous was not completely detached. All this led him to the diagnosis of a stage 3 macular hole. The patient was scheduled for surgery the next month.

When the decision to operate on a full-thickness macular hole is taken, surgery is usually scheduled relatively soon. However, this is not a "same week emergency" since improvement of visual acuity has been observed on holes treated even one year after detachment. ${ }^{7} \mathrm{~A}$ faster intervention is still believed to result in better visual recovery. That is why our patient was seen by the specialist one month after referral and was scheduled for surgery about one month later.
Retinal hole surgery is a very rewarding surgery because visual acuity can improve dramatically following the procedure. Final visual acuity of $6 / 12(20 / 40)$ or better is achieved in $65 \%$ of cases. ${ }^{4}$ This is very significant since preop acuity can be as low as $6 / 120$ (20/400). FTMH closure rates as high as 85 to $100 \%$ have been reported. ${ }^{8-11} \mathrm{~A}$ few years ago, such a positive visual outcome might have seemed surprising, since it was believed that some of the neuroretinal tissue had been lost in the "operculum" which floated above the macula. It is now established that this is rather a "pseudo-operculum" that consists of contracted prefoveal cortical vitreous and that no neural tissue is usually "torn off" the retina. The hole is actually a tear in the retina and when it is once again closed, the macula becomes almost whole again, though not as precisely organized as before. Hence, visual function is close to normal.

In the present case, the retina specialist chose to proceed with cataract extraction beforehand. Not only did he consider that at age 65 she already presented some degree of nuclear sclerosis, but also that many patients will develop a significant cataract in the two years following a macular hole surgery. ${ }^{11} \mathrm{He}$ then performed pars plana vitrectomy and peeled the inner limiting membrane to ensure that no traction remained on the macula. The efficacy of these procedures in the case of macular hole surgery has been proven in numerous studies. ${ }^{12-14}$ Finally, although the use of short-term tamponade with $\mathrm{SF}(6)$ over prolonged tamponade (with $\mathrm{C}(3) \mathrm{F}(8)$ or silicone oil) is still debated, ${ }^{15}$ our surgeon elected to use the former option because it has proven more effective in his experience. Still, this remains a challenging procedure for the surgeon since the initial reattachment rate after PPV with gas tamponade ranges from $40 \%$ to $93.5 \%$. $^{2}$ In this case, the intervention was successful and the visual outcome of $6 / 12+2$ $(20 / 40+2)$ BCVA was to the complete satisfaction of both the patient and the surgeon. However, even with positive resolution for the affected eye, the patient should monitor the other eye and have regular follow-ups since involvement of the fellow eye at five years is about $10-15 \%$. 40

When reattachment is achieved, post-op VA is often very good and it continues to improve over a period that sometimes exceeds one year after the surgery. ${ }^{16}$ Recovery is very quick during the first month, as the tamponade dissolves. Visual acuity progresses more slowly during the following months. Evidence obtained with the OCT seemed to indicate that visual recovery is the result of reorganization of the photoreceptor layer. ${ }^{17-19}$ The advent of spectral domain OCT facilitated the observation of this process. Instead of the scanning beam that is used in time domain OCT, in spectral domain OCT, the interference pattern between the reference and sampling beam is decomposed into a spectrum. Since each wavelength has a different focal length, different loci of the tissue under examination 


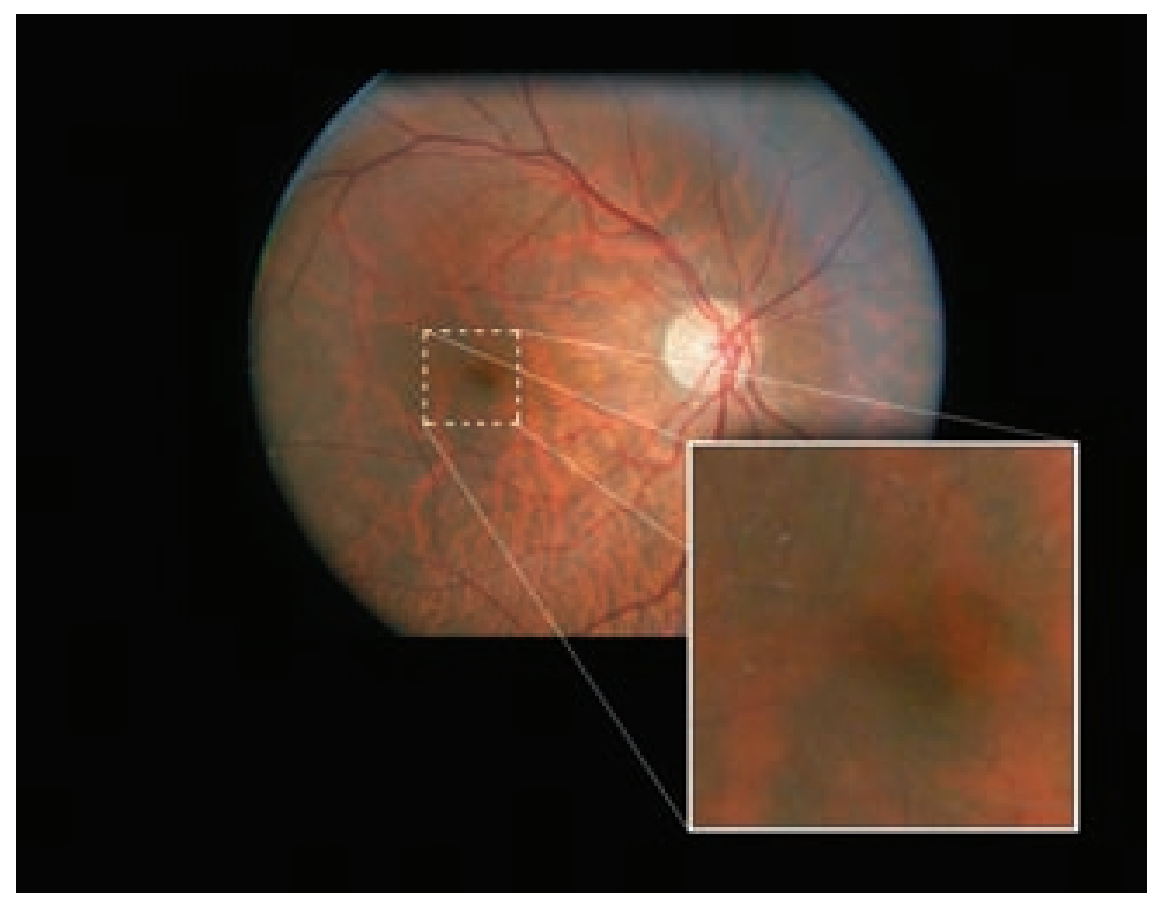

Figure 5 - Fundus photography shows a closed macular hole with no infiltration in the right eye.

are scanned simultaneously. This allows a sampling rate up to a 100 time faster and permits capture of details of cellular structures (up to $5 \mu \mathrm{m}$ ), which are normally blurred at the sampling speed of time domain OCT. ${ }^{20,21}$ More recent studies that took advantage of this technology confirmed the hypothesis of photoreceptor reorganization following macular hole surgery. ${ }^{22-24}$ The defect diameter at the junction of the inner and outer segments of the affected photoreceptors ${ }^{3,24}$ and outer foveal thickness were the elements of OCT scans most strongly correlated with post-op BCVA. ${ }^{3}$ Shimozono et al. (2010) hypothesized that there is an elongation of the outer segment of the photoreceptors when they are reattached, which would account for increased outer retinal thickness. ${ }^{3}$

\section{Conclusion}

Early identification of a full thickness macular hole is not always straightforward for clinicians who are not regularly exposed to the condition. For the patient, visual acuity is very significantly reduced and there may be a small central absolute scotoma. Traditionally, diagnosis was made after careful examination of the macular region with the slit lamp and a fundus lens, and was subjectively confirmed by the Watzke-Allen sign. This required a lot of skill from the examiner. However, new technologies such as OCT greatly facilitate the differential diagnosis with other macular conditions. The interventions needed (Pars plana vitrectomy, peeling of the inner limiting membrane and gas tamponade) all require a very skilled surgeon, but when they are successful, visual recovery is often dramatic even if the intervention is performed many months after the formation of the hole. In this regard, a macular hole is not a "same week" ocular emergency. However, as seen in this case, having facilitated access to retinal services may lead to adequately prompt referral. This in turn is reassuring for the patient who, despite being given the proper information about his condition, may fear total loss of vision in the affected eye.

\section{References}

1. Odrobina D, Michalewska Z, Michalewski J, Dziegielewski K, Nawrocki J. Long-term evaluation of vitreomacular traction disorder in spectral-domain optical coherence tomography. Retina 2011;31(2):324-31.

2. Hong MC, Wu TT, Sheu SJ. Primary gas tamponade in the management of macular hole with retinal detachment in highly myopic eyes. J Chin Med Assoc 2011;74(3):121-4. Epub 2011 Feb 25.

3. Shimozono M, Oishi A, Hata M, Kurimoto Y. Restoration of the photoreceptor outer segment and visual outcomes after macular hole closure: spectral-domain optical coherence tomography analysis. Graefes Arch Clin Exp Ophthalmol 2011 Apr 17. [Epub ahead of print]

4. Kanski JJ. Clinical Ophthalmology: A Systematic Approach. 6th Ed. Philadelphia, PA: ButterworthHeinemann; 2003:645-647.

5. Friedman NJ, Kaiser PK, Pineda II R. The Massachusetts Eye and Ear Infirmary Illustrated Manual of Ophthalmology. 3rd Ed. USA: Saunders; 2009:385-388. 
6. Spiritus A, Dralands L, Stalmans P, Stalmans I, Spileers W. OCT study of fellow eyes of macular holes. Bull Soc Belge Ophtalmol 2000;275:81-4.

7. Kim NM, Park HJ, Koo GH, Lee JE, Oum BS. Photoreceptor layer assessed in tissue layer imaging using spectraldomain optical coherence tomography after surgical closure of macular hole. Retina. 2011 Feb 23. [Epub ahead of print].

8. Benson WE, Cruickshanks KC, Fong DS, Williams GA, Bloome MA, Frambach DA, Kreiger AE, Murphy RP. Surgical management of macular holes: a report by the American Academy of Ophthalmology. Ophthalmology 2001;108(7):1328-35.

9. Tognetto D, Grandin R, Sanguinetti G, Minutola D, Di Nicola M, Di Mascio R, Ravalico G. Internal limiting membrane removal during macular hole surgery: results of a multicenter retrospective study. Ophthalmology 2006;113(8):140110.

10. Mester V, Kuhn F. Internal limiting membrane removal in the management of full-thickness macular holes. Am J Ophthalmol 2000;129(6):769-77.

11. Lahey JM, Francis RR, Fong DS, Kearney JJ, Tanaka S. Combining phacoemulsification with vitrectomy for treatment of macular holes. $\mathrm{Br} \mathrm{J}$ Ophthalmol 2002;86(8):876-8.

12. Uemoto R, Yamamoto S, Tsukahara I, Takeuchi S. Efficacy of internal limiting membrane removal for retinal detachments resulting from a myopic macular hole. Retina 2004;24(4):560-6.

13. Mochizuki Y, Enaida H, Hisatomi T, Hata Y, Miura M, Arita R, Kawahara S, Kita T, Ueno A, Ishibashi T. The internal limiting membrane peeling with brilliant blue $G$ staining for retinal detachment due to macular hole in high myopia. Br J Ophthalmol 2008;92(7):1009.
14. Kwok AK, Lai TY. Internal limiting membrane removal in macular hole surgery for severely myopic eyes: a case-control study. Br J Ophthalmol 2003;87(7):885-9.

15. Georgalas I, Ladas I, Petrou P, Gotzaridis E, Papaconstantinou D, Rouvas A, Koutsandrea C. Does sulfur-hexafluoride tamponade, as an adjunct to vitrectomy and internallimiting-membrane peeling, suffice for the treatment of retinal detachment associated with macular hole? Cutan Ocul Toxicol 2010;29(4):288-92. Epub 2010 Sep 22

16. Leonard RE 2nd, Smiddy WE, Flynn HW Jr, Feuer W. Long-term visual outcomes in patients with successful macular hole surgery. Ophthalmology 1997;104(10):1648-52.

17. Lee JE, Lee SU, Jea SY, et al. Reorganization of photoreceptor layer on optical coherence tomography concurrent with visual improvement after macular hole surgery. Korean J Ophthalmol 2008;22:137-142.

18. Villate N, Lee JE, Venkatraman A, Smiddy WE. Photoreceptor layer features in eyes with closed macular holes: optical coherence tomography findings and correlation with visual outcomes. Am J Ophthalmol 2005;139:280-289.

19. Baba T, Yamamoto S, Arai M, Arai E, Sugawara T, Mitamura Y, Mizunoya. Correlation of visual recovery and presence of photoreceptor inner/outer segment junction in optical coherence images after successful macular hole repair. Retina. 2008;28(3):453-8.

20. Drexler W, Sattmann H, Hermann B, Ko TH, Stur M, Unterhuber A, Scholda C, Findl O, Wirtitsch M, Fujimoto JG, Fercher AF. Enhanced visualization of macular pathology with the use of ultrahigh-resolution optical coherence tomography. Arch Ophthalmol 2003;121(5):695-706.
21. Ko TH, Fujimoto JG, Schuman JS, Paunescu LA, Kowalevicz AM, Hartl I, Drexler W, Wollstein G, Ishikawa H, Duker JS (2005) Comparison of ultrahigh- and standard-resolution optical coherence tomography for imaging macular pathology. Ophthalmology 112:1922.

22. Inoue $M$, Watanabe $Y$, Arakawa $A$, et al. Spectral-domain optical coherence tomography images of inner/outer segment junctions and macular hole surgery outcomes. Graefes Arch Clin Exp Ophthalmol 2009;247:325-330.

23. Christensen UC, Kroyer K, Sander B, et al. Prognostic significance of delayed structural recovery after macular hole surgery. Ophthalmology 2009;116:2430_ 2436.

24. Sano M, Shimoda Y, Hashimoto H, Kishi S. Restored photoreceptor outer segment and visual recovery after macular hole closure. Am J Ophthalmol 2009;147:313-318. 